\title{
LA ATENCIÓN A LA DEPENDENCIA COMO MOTOR DE DESARROLLO ECONÓMICO
}

\section{DEPENDENCY CARE AS A DRIVER OF ECONOMIC DEVELOPMENT}

\author{
Belén Díaz Díaz belen.diaz@unican.es \\ Universidad de Cantabria. España.
}

\begin{abstract}
RESUMEN
El envejecimiento de la población en la mayoría de los países desarrollados marca la necesidad de establecer políticas de actuación que garanticen la atención a dicha población. Para ello, se debe desterrar la idea de que los recursos destinados a la dependencia son un gasto, considerarlos como una inversión que contribuye al desarrollo económico y que puede cuantificarse en términos de impacto en la generación de empleo y riqueza. Este estudio analiza el impacto económico del conjunto de centros de atención a la dependencia (tanto residenciales como de atención diurna) en la región de Cantabria (España), así como del Servicio de Ayuda a Domicilio. De manera directa, la atención a la dependencia genera 24 empleos por cada millón de euros invertido por la Administración en el sector. Si incluimos el impacto indirecto e inducido, esta generación de empleo se eleva a 36, con el consiguiente efecto sobre la producción, el consumo y la recaudación de impuestos.
\end{abstract}

\section{Palabras Clave}

Atención a la dependencia; Centros de atención a discapacitados; Centros de atención a mayores; Impacto económico; Tablas input-output.

\begin{abstract}
The aging of the population in most developed countries makes necessary to establish action policies to ensure care for this population. In order to achieve this aim, the idea that allocating money to dependency is a expenditure must be banished and consider it as an investment that contributes to economic development and can be quantified in terms of impact on employment generation and wealth. This study analyses the economic impact of the dependency care (given through residential care centres or day care centres) in the region of Cantabria (Spain), as well as of the Home Care System. Dependency care generates directly 24 jobs for every million EUR invested by the Administration in this sector. If we include the indirect and induced impact, the job creation rises to 36 jobs, with the consequent effect in production, consumption and tax revenues.
\end{abstract}

\section{KEYWORDS}

Dependency Care; Economic Impact; Input-Output Tables; Elderly Care Centres; Care Centres for Disabled. 


\section{INTRODUCCIÓN}

Desde hace décadas Europa y España están viviendo un importante cambio demográfico caracterizado por el envejecimiento de la población, la reducción de la natalidad y la internacionalización de la población a través de procesos migratorios. Según Birg (2009), el impacto económico del cambio demográfico consiste en una reducción de la riqueza causada por la menor tasa de crecimiento del producto nacional y por la menor tasa de crecimiento de la renta per cápita.

Existe una creciente preocupación de los gobiernos por el potencial impacto negativo del envejecimiento de la población en los sistemas sociales y de salud de los países. Una población mayor y dependiente tiene consecuencias económicas, tales como la sostenibilidad del sistema de pensiones (Mirlees 1997; Comisión Europea 2012) o los mayores costes sanitarios (Fries et al. 1998; Harvey y Thurnwald 2009). El ratio de dependencia (número de personas mayores de 65 años dividido de la población activa) aumentará en todas las economías de la OCDE, convirtiéndose en un problema crítico para las finanzas públicas. El gasto en pensiones como porcentaje del PIB ha aumentado en la UE-15 desde el $6 \%$ en 1960 hasta más del $12 \%$ en el año 2000, y bajo la hipótesis de que no se acometiera ninguna acción para reconducir esta situación, Gal (2008) estima que el gasto en pensiones podría llegar a niveles insostenibles próximos al $20 \%$ en las próximas décadas. Según datos de Eurostat (2013) el gasto en pensiones sobre el PIB ascendió en 2007 en EU-27 a 10,1 \% y se prevé un incremento de hasta el 12,5\% en 2060. Sin embargo, la situación no es igual para todos los países. En el caso de España los datos apuntan a un aumento desde el $8,4 \%$ en 2007 al $15,1 \%$ previsto para 2060 .

Tanto el envejecimiento de la población como la mayor demanda de servicios sociales hacen que los gobiernos destinen cada vez más recursos a la atención a la dependencia. Sin embargo, se hace necesario revisar los paradigmas que consideran a los recursos destinados a la atención a la dependencia como gasto social y sustituirlos por otros que consideren dichos recursos como inversión social, uniendo los objetivos sociales con el crecimiento de la actividad económica y el empleo. Por lo tanto, la atención a la dependencia se convierte en una oportunidad para explorar diferentes sectores económicos que pueden impulsar el crecimiento y así reducir el impacto negativo del envejecimiento de la población sobre la renta per cápita (Fougere y Merette 1999).

Para ello, el presente estudio analiza empíricamente los retornos económicos que genera la inversión en servicios sociales derivados del ahorro en prestaciones de desempleo, incremento de la recaudación por cotizaciones sociales y de los ingresos fiscales, vía Impuesto sobre el Valor Añadido (IVA), Impuesto sobre la Renta de las Personas Físicas (IRPF) e Impuesto de Sociedades (IS). Se considera una muestra de 8.544 plazas autorizadas en 152 centros de atención a la dependencia en la región de Cantabria, en España.

En los últimos años se han realizado estudios que analizan el impacto económico de la atención a la dependencia y que presentan algunas limitaciones, tanto metodológicas 
como de orientación, por centrarse en servicios de atención a la dependencia específi$\cos$ (residencial o discapacidad). El presente estudio trata de salvar estas limitaciones abarcando el análisis de todos los servicios de atención a la dependencia y utilizando la metodología de Leontief para valorar el impacto económico. En particular:

- Se analizan los distintos servicios de atención a la dependencia, incluyendo las siguientes categorías: residencia para mayores, centro de día para mayores, residencia $24 \mathrm{~h}$ para personas con discapacidad, residencia de atención básica para discapacitados, centro de día para discapacitados, centro ocupacional, centro de rehabilitación psicosocial, así como el sistema de ayuda a domicilio. De esta manera, se podrá apreciar el impacto económico global de la atención a la dependencia sin restar importancia a ninguno de los servicios.

- Se analiza el impacto económico de los servicios de atención a la dependencia desagregado en sus tres componentes: 1) Impacto directo: derivado de la actividad directa que realizan los centros de atención a la dependencia en términos de producción y empleo; 2) Impacto indirecto: derivado de la demanda de estos centros a otros proveedores; 3) Impacto inducido: derivado del incremento en el consumo que producen las rentas de los trabajadores tanto por el impacto directo como indirecto.

- El estudio de basa en la metodología de Leontief, utilizando las tablas inputoutput $^{1}$ de la economía regional para estimar el impacto que la demanda de esta actividad genera sobre los principales agregados macroeconómicos (producción y empleo), sobre la recaudación de impuestos y sobre los ingresos de la Seguridad Social.

El impacto económico del gasto público adquiere especial relevancia en el contexto económico actual, caracterizado por la recesión, el debate sobre los recortes en el gasto público y la necesidad de que los gobiernos estimulen la demanda agregada.

En particular, la realización de este estudio centrado en el impacto económico de la atención a la dependencia tiene una serie de implicaciones que resultan de utilidad para la toma de decisiones y el desarrollo de políticas públicas relacionadas con este sector. El estudio permite:

1. Obtener una visión general de las actividades ligadas a la atención a la dependencia como generadoras de riqueza.

2. Contar con una herramienta de apoyo a la toma de decisiones. El "estudio de impacto económico" es una herramienta para las administraciones que prestan servicios a las personas dependientes y sus familias, dando apoyo para la toma

${ }^{1}$ Las tablas input-output son un instrumento estadístico por el que se desagrega la producción nacional entre los sectores que la han originado y los sectores que la han absorbido. 
de decisiones de gestión, de inversión y de políticas públicas, así como para la puesta en marcha y/o potenciación de nuevos sectores o actividades.

3. Conocer los sectores de la economía más beneficiados por las actividades ligadas a la atención a la dependencia. Los agentes públicos y privados que trabajan en torno a la atención a la dependencia podrán valorar cuáles de sus actividades tienen un mayor impacto en términos cuantitativos.

4. Valorar los retornos a la Hacienda Pública y a la Seguridad Social. Las actividades ligadas a la atención a la dependencia repercuten en los ingresos que percibe la Hacienda Pública en concepto de IVA, IRPF e Impuesto de Sociedades y en el sistema de la Seguridad Social.

5. Potenciar la imagen y el reconocimiento público del sector de atención a la dependencia como elemento clave para la competitividad del país. Ayudar a identificar el sector de atención a la dependencia y sus familias como elemento tractor de la economía desde la perspectiva de la innovación, las oportunidades de creación de un tejido empresarial, los servicios, etc., y evaluar la conveniencia de desarrollar políticas públicas de apoyo al sector.

Este estudio ofrece una nueva perspectiva del gasto social destinado a la atención de mayores y discapacitados, al entenderlo no solo como vehículo de bienestar individual y colectivo o como elemento de cohesión social, sino que además se considera necesario y relevante para el desarrollo del tejido productivo de una región o de un país.

A continuación, el artículo se estructura de la siguiente manera: el apartado 2 recoge la evidencia observada en estudios previos que analizan el impacto económico de la atención a la dependencia en España. El apartado 3 se centra en la región de Cantabria y analiza las características del gasto en atención a la dependencia, pasando en el apartado 4 a describir la muestra, fuentes de información y metodología para llevar a cabo el estudio. El apartado 5 recoge los principales resultados obtenidos del impacto directo y el apartado 6 los resultados del impacto indirecto e inducido. Por último, el apartado 7 plantea las principales conclusiones de estudio.

\section{LA ATENCIÓN A LA DEPENDENCIA Y SU IMPACTO ECONÓMICO EN ESPAÑA}

\section{La atención a la dependencia y la generación de empleo}

La atención a las personas con dependencia se concreta fundamentalmente en actividades de cuidados personales, las cuales son muy intensivas en mano de obra. De acuerdo con el Libro blanco de la dependencia (2004), la mayoría de esos empleos benefician a colectivos que tienen especiales dificultades de inserción laboral (mujeres, trabajadores con escasa cualificación, desempleados de larga duración, jóvenes en busca de su primer empleo y trabajadores de más de 45 años), lo que contribuye a 
bajar la tasa de desempleo, subir la tasa de actividad, luchar contra la temporalidad y disminuir el número de hogares en los que todos sus miembros activos están en situación de desempleo.

Anualmente las familias españolas dedican más de nueve mil millones de horas de trabajo no remunerado (equivalente a unos 5,2 millones de puestos de trabajo a tiempo completo) al cuidado de personas mayores y enfermas. El 80 \% de este trabajo es realizado por mujeres (Durán 2001).

A partir de previsiones sobre el número de dependientes en España y las necesidades de personal para su atención, el Libro blanco de la dependencia estima la generación de empleo derivada de la atención a la dependencia. En particular, llega a las siguientes conclusiones:

- El número de personas dependientes en 2010 se estimaba en 1.245 .000 y el número de personas no dependientes con necesidad de ayuda para realizar tareas domésticas y/o discapacidad moderada para alguna actividad básica de la vida diaria se estimaba en cerca de dos millones.

- La previsión de generación de empleo bruto en el horizonte 2010 se establecía en 352.235 puestos de trabajo a jornada completa (la generación neta de empleo, una vez descontados los puestos de trabajo que en 2004, momento de redacción del Libro Blanco, se dedican a la atención de personas dependientes es de 262.735).

- En total, el efecto potencial sobre el empleo derivado de la implantación del Sistema Nacional de Dependencia (SAAD), en el horizonte 2010, se cifraba en más de 450.000 empleos equivalentes a jornada completa, incluyendo los efectos indirectos e inducidos de la actividad y la afloración del empleo sumergido.

El estudio de Rodríguez y Jiménez (2010) evalúa el impacto sobre el empleo que entre 2007 y 2009 ha provocado la implantación del SAAD. En estos tres años 184.815 personas se han dado de alta en la Seguridad Social en el sector de los servicios sociales (asistencia en establecimientos residenciales y actividades de servicios sociales sin alojamiento). El ritmo de crecimiento en el empleo es inferior a lo previsto en el Libro blanco básicamente por dos motivos:

- La profunda crisis económica.

- La proliferación de las prestaciones económicas para cuidados en el medio familiar.

Aunque estas últimas no generan por sí mismas empleo, pueden tener algunos efectos indirectos sobre el nivel de actividad económica y laboral, por cuanto suponen una transferencia de renta a la persona dependiente y a su familia, que en parte se trasladará al consumo. 
Estos autores estiman además el potencial bruto de generación de empleo derivado de la atención a las personas en situación de dependencia, sin descontar el empleo que ya existía en el sector con anterioridad a la puesta en marcha del SAAD y suponiendo un escenario en el que todas las personas dependientes, cualquiera que fuera su grado, estarían atendidas por algún tipo de servicio.

Los resultados de la estimación señalan casi 500.000 puestos de trabajo en 2011 y por encima de 635.000 en 2015 (expresados en términos de empleo equivalente a jornada completa).

La generación de empleo y las retribuciones que se originan tienen un importante efecto en la recaudación de impuestos vía IRPF y en las cotizaciones a la Seguridad Social. En particular, las retribuciones al personal suponen el coste principal de los centros de atención a la dependencia, variando porcentualmente de unos estudios a otros. Así, mientras Deloitte (2006) establece porcentajes entre el $50 \%$ y el $63 \%$ (dependiendo de la Comunidad Autónoma), Codorniu (2005) establece un porcentaje del $70 \%$, el Institut d'Estadística de Catalunya (2002) lo establece en 63,2 \%, el Centro Europeo de Empresas e Innovación de Navarra, CEIN (2003) en el 56 \% y el Centro Europeo de Empresas e Innovación de Galicia, BIC (2008) en el 40 \%.

\section{Impacto económico de la atención a la dependencia}

Desde mediados de los años 90 se han venido desarrollando distintos estudios con el objetivo de analizar el impacto económico del gasto en políticas sociales, no solo en términos de empleo sino también en términos de producción, impuestos y Seguridad Social.

Los trabajos desarrollados previamente en distintos ámbitos geográficos de España y en los que se analizan distintos aspectos de la política social (incluida la atención a la dependencia) se señalan en la tabla 1.

A efectos comparativos, entre los estudios se calculan distintos valores y ratios que permitan comparar el impacto del coste en atención a la dependencia sobre el número de beneficiarios, la reversión a la Administración Pública, el PIB o el empleo. Como se comenta a continuación, existe una gran disparidad entre los valores observados dependiendo de la región y la metodología empleada.

En la tabla 1 se observa como el coste que asume la Administración Pública ${ }^{2}$ por beneficiario de la atención a la dependencia varía de unas regiones a otras, oscilando entre el mínimo de 5.828,13 euros del País Vasco y el máximo de 12.650 de la Comunidad Valenciana. En Cantabria esta cantidad ronda los 11.000 euros.

Asimismo, la tabla 1 muestra el impacto directo, indirecto e inducido de las políticas sociales sobre el PIB, que llega a suponer cerca de dos veces el coste asumido en

${ }^{2}$ El coste asumido por la Administración del total de coste que supone la atención a la dependencia se encuentra entre el $61 \%$ y el $65 \%$, dependiendo de la región. 
Tabla 1.

Estudios previos sobre el impacto económico de las políticas sociales.

\begin{tabular}{|c|c|c|c|c|c|c|}
\hline $\begin{array}{l}\text { Ámbito } \\
\text { de estudio }\end{array}$ & Álava & País Vasco & España & País Vasco & $\begin{array}{l}\text { Comunidad } \\
\text { Valenciana }\end{array}$ & Guipúzcoa \\
\hline Referencia & $\begin{array}{c}\text { Centro de } \\
\text { Documentación } \\
\text { y Estudios, SIIS } \\
(1994)\end{array}$ & $\begin{array}{c}\text { Centro de } \\
\text { Documentación } \\
\text { y Estudios, SIIS } \\
\text { (1999) }\end{array}$ & $\begin{array}{c}\text { Libro Blanco } \\
\text { de la } \\
\text { Dependencia } \\
(2004)\end{array}$ & $\begin{array}{l}\text { Federación } \\
\text { Vasca de } \\
\text { Asociaciones } \\
\text { en favor de las } \\
\text { Personas con } \\
\text { Discapacidad } \\
\text { Intelectual, } \\
\text { FEVAS (2007) }\end{array}$ & \begin{tabular}{|c|} 
\\
Federación \\
Empresarial de \\
Asistencia a la \\
Dependencia, \\
FED (2010)
\end{tabular} & $\begin{array}{c}\text { Zubiri et al. } \\
\text { (2010) }\end{array}$ \\
\hline Año analizado & 1992 & 1997 & $2005-2010$ & 2005 & 2010 & 2009 \\
\hline $\begin{array}{l}\text { Sector } \\
\text { analizado }\end{array}$ & $\begin{array}{l}\text { Servicios } \\
\text { Sociales }\end{array}$ & $\begin{array}{l}\text { Servicios } \\
\text { Sociales }\end{array}$ & $\begin{array}{c}\text { Sistema } \\
\text { Nacional de } \\
\text { Dependencia }\end{array}$ & $\begin{array}{l}\text { Discapacidad } \\
\text { Intelectual }\end{array}$ & $\begin{array}{l}\text { Servicio } \\
\text { Residencial }\end{array}$ & $\begin{array}{l}\text { Política } \\
\text { social }\end{array}$ \\
\hline Beneficiarios & 7.777 & 40.136 & 1.246 .428 & 21.000 & 4.000 & 30.000 \\
\hline Metodología & $\begin{array}{c}\text { Tabla I-O regio- } \\
\text { nal aplicada a } \\
\text { una provincia }\end{array}$ & $\begin{array}{l}\text { Extrapola los } \\
\text { resultados } \\
\text { obtenidos en } \\
\text { SIIS (1994) a la } \\
\text { región }\end{array}$ & & $\begin{array}{l}\text { Tabla I-O } \\
\text { regional }\end{array}$ & & $\begin{array}{l}\text { Tabla I-O } \\
\text { regional } \\
\text { aplicada } \\
\text { a una } \\
\text { provincia }\end{array}$ \\
\hline $\begin{array}{l}\text { Coste } \\
\text { Administración } \\
\text { Pública por } \\
\text { beneficiario }\end{array}$ & $7.812,25$ & $9.592,39$ & & $5.828,13$ & $12.650,00$ & $11.153,33$ \\
\hline $\begin{array}{l}\text { PIB/ } \\
\text { Coste Total }\end{array}$ & & & & 1,23 & & 1,97 \\
\hline $\begin{array}{l}\text { Empleo/ } \\
\text { Coste AP* }\end{array}$ & 41,40 & 42,08 & & $77,21^{* *}$ & $26,51^{\cdots * *}$ & 22,71 \\
\hline $\begin{array}{l}\text { Empleo/ } \\
\text { Beneficiario }\end{array}$ & 0,32 & 0,40 & 0,28 & 0,45 & 0,55 & 0,25 \\
\hline $\begin{array}{l}\text { Reversión/ } \\
\text { Coste AP }\end{array}$ & 0,43 & 0,43 & & $1,24^{*+* * *}$ & 1,26 & 0,45 \\
\hline
\end{tabular}

*Empleo generado por cada millón de coste asumido por la Administración Pública.

** Considerando que el coste que asume la Administración Pública supone un $65 \%$ del coste total de la atención a la dependencia.

*** En los ratios de empleo se contemplan únicamente los empleos directos generados.

${ }^{* * * *}$ Teniendo en cuenta que el coste que asume la Administración Pública supone un $65 \%$ del coste total de la atención a la dependencia.

Fuente: Elaboración propia. 
Guipúzcoa. En el estudio realizado para el País Vasco (Federación Vasca de Asociaciones a favor de las Personas con Discapacidad Intelectual o del Desarrollo 2007), este multiplicador desciende a 1,23.

En relación con el empleo, se generan entre 23 y 77 puestos de trabajo por millón de euros invertido en política social por la Administración Pública. Asimismo, el ratio "trabajadores sobre beneficiarios" oscila entre 0,25 y 0,55, valor este último que resulta elevado si tenemos en cuenta el valor medio de este ratio (aproximadamente el 0,3 ) en los diferentes estudios, que señalaría la creación de 3 puestos de trabajo por cada 10 beneficiarios de esta política social.

Por último, se ha calculado el ratio "Reversión/Coste Administración Pública (AP)" que señala el porcentaje del gasto en políticas sociales que revierte directamente a la Administración Pública de nuevo, a través de la recaudación de impuestos y las aportaciones a la Seguridad Social, así como del ahorro en las prestaciones por desempleo.

Los sueldos y salarios del personal vinculado directamente a la atención a la dependencia permiten recuperar buena parte del gasto realizado en el sector a través de la recaudación del IRPF y las cotizaciones a la Seguridad Social. De hecho, estas dos partidas vienen a representar el $73,4 \%$ del total de la recaudación derivada del gasto en política social (Zubiri et al. 2010). El resto de la recaudación proviene de un incremento en el IVA, derivado de la mayor demanda de bienes y servicios, y en el Impuesto de Sociedades, derivado del beneficio generado por las empresas tanto directa como indirectamente a través de su impacto en otros sectores.

En los estudios recogidos en la tabla 1, el ratio "Reversión/Coste Administración Pública" oscila entre el $43 \%$ y el $126 \%$. En este último caso, la cantidad que revierte a la Administración Pública está por encima de los costes asumidos, dando lugar a un excedente, o lo que es lo mismo "de cada euro de gasto en política social se genera 1,26 euros de recaudación (vía impuestos y Seguridad Social)"3.

\footnotetext{
${ }^{3}$ Los dos estudios que muestran una reversión por encima del $100 \%$ (Federación Vasca de Asociaciones a favor de las Personas con Discapacidad Intelectual o del Desarrollo 2007 y Federación Empresarial de Asistencia a la Dependencia 2010) presentan alguna limitación. El primero incluye un efecto inducido que no se generará en un solo año, por lo que se sobreestima el retorno considerando que se produce anualmente; y el segundo presenta una sobreestimación del retorno vía ahorro en prestaciones de desempleo, considerando que todos los trabajadores en atención a la dependencia estarían cobrando la prestación por desempleo de no existir estos servicios.
} 


\section{Gráfico 1.}

Efecto sobre la recaudación del gasto en política social.

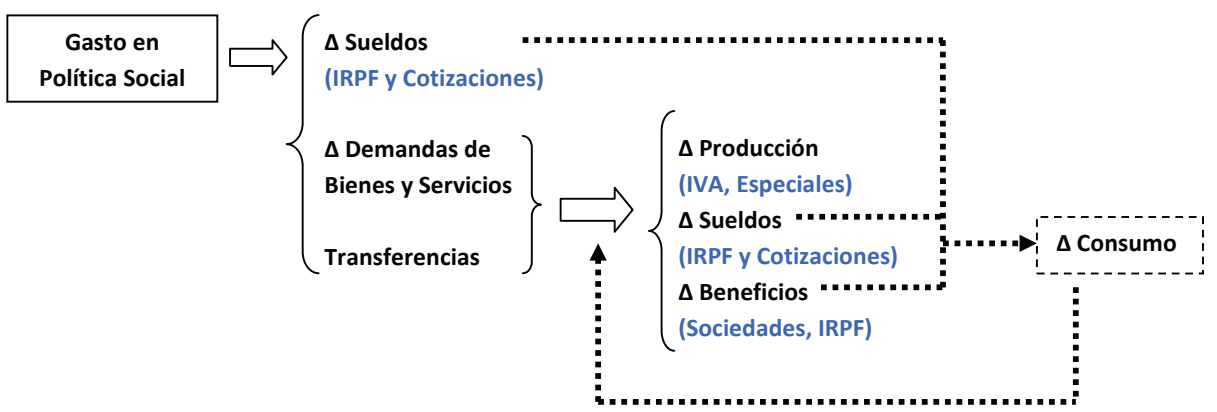

Fuente: Zubiri et al. (2010).

\section{Características básicas del gasto en atención a la dependencia en CANTABRIA}

Para cuantificar el impacto económico del gasto en atención a la dependencia de Cantabria es necesario analizar previamente sus características económicas y distributivas, y a quién beneficia este gasto.

\section{Distribución económica del gasto y beneficiarios}

En 2010 el gasto en atención a la dependencia ${ }^{4}$ en Cantabria superó los 130 millones de euros, lo que representa el $0,78 \%$ del PIB de Cantabria ${ }^{5}$ y el $4,23 \%$ de los presupuestos generales.

La distribución de este gasto aparece reflejada en la tabla 2, donde la partida principal son las transferencias corrientes, que suponen el $76,7 \%$ del total. Dentro de estas transferencias el principal coste se refiere a las estancias concertadas con residencias privadas. Cantabria ha optado por un modelo de residencias privadas concertadas con el sector público en vez de un modelo basado en residencias de titularidad pública, de ahí que esta partida represente el $45,25 \%$ del total del gasto.

El presupuesto destinado al Servicio de Ayuda a Domicilio agregaría al gasto de atención a la dependencia 9,1 millones de euros.

\footnotetext{
${ }^{4}$ Incluidos todos los grados y niveles de dependencia, pero sin incluir el Servicio de Ayuda a Domicilio.

${ }^{5}$ En España se destina un 1,05 \% del PIB a dependencia, frente al 1,45 \% de la Unión Europea.
} 
Tabla 2.

Coste del Programa de Atención a Personas Dependientes.

\begin{tabular}{lcccc}
\hline & $2009(€)$ & $2009(\%)$ & $2010(€)$ & $2010(\%)$ \\
\hline Gastos de personal $^{*}$ & 25.145 .500 & 23,8 & 25.114 .932 & 19,3 \\
Gastos corrientes* $^{* *}$ & 4.503 .220 & 4,3 & 5.223 .220 & 4,0 \\
Transferencias corrientes $^{* * *}$ & 75.957 .719 & 71,9 & 100.020 .261 & 76,7 \\
Total & 105.606 .439 & 100,0 & 130.358 .413 & 100,0 \\
\hline
\end{tabular}

* Incluye tanto los trabajadores ligados a la gestión como el personal de los cinco centros públicos que tiene el Gobierno de Cantabria (cuatro residencias y un centro de día). El impacto económico de estos salarios se manifiesta a través de los impuestos y gastos de consumo que realizan los perceptores de estos salarios.

" Incluye los consumos de inputs intermedios realizados directamente por el Programa de Atención a Personas Dependientes (incluidos los de los centros del gobierno). Su impacto económico se produce por la vía de aumentar la demanda de bienes y servicios de determinados sectores.

*** Incluyen las transferencias a Sociedades, Entidades Públicas empresariales, Fundaciones (8,8 $\%$ del importe total de transferencias en 2010), a entidades locales a través del concierto del servicio de Asistencia Domiciliaria o la Teleasistencia $(9,6 \%$ ) y las transferencias a familias e instituciones sin fines de lucro $(81,6 \%)$. Dentro de esta última partida, además de las estancias concertadas se incluyen las Prestaciones del Sistema para la Autonomía y Atención a Personas Dependientes, que ascienden a 20.000.000 EUR, representando un $15,34 \%$ del total del gasto, y que tendrán efectos económicos a través del consumo adicional que generan.

Fuente: Elaboración propia a partir de los Presupuestos Generales de Cantabria.

En Cantabria, los últimos datos publicados correspondientes a la Encuesta sobre Discapacidades, Autonomía Personal y Situaciones de Dependencia (Instituto Cántabro de Estadística 2008), ponen de manifiesto la existencia de un 6,4 \% de la población con algún tipo de discapacidad 6 .

Asimismo, el porcentaje de mayores de 80 años sobre la población total se ha ido incrementando en los últimos años, pasando de un 4,1 \% de la población en 1996 al 6 \% en 2010 , de los que un $41 \%$ eran dependientes.

En este escenario, si consideramos como beneficiarios de la atención a la dependencia únicamente aquellos que reciben algún tipo de prestación directa, en Cantabria existen 11.955 personas beneficiarias (con datos a julio de 2010), lo que representa el $2 \%$ de la población de la región.

${ }^{6}$ En total, en 2008 hay 37.500 personas con discapacidad sobre una población total de 582.132 personas en Cantabria. 


\section{La atención a la dependencia en la estructura productiva en Cantabria}

Para contextualizar el sector de la atención a la dependencia en la economía regional, se explora brevemente la estructura productiva de Cantabria de acuerdo con los datos del Instituto Cántabro de Estadística (ICANE). En el segundo trimestre de 2011 el sector más importante es el de los servicios, que aporta el $61,9 \%$ del PIB (dentro de este sector se encuentra la atención a la dependencia). El de industria y energía aporta el 18,7 \%; la construcción el 9,5\%; la agricultura, ganadería y pesca el 2,5\%. Esta estructura se mantiene similar desde 2007.

La distribución porcentual del empleo en Cantabria por sectores de actividad muestra como el sector servicios absorbe el 65,5\% de la mano de obra (3,6 puntos por encima de su participación en el PIB), lo que muestra que los servicios son más intensivos en mano de obra que otros sectores como la industria y la energía. Por lo tanto, no se debe despreciar a los servicios, y en particular a los servicios sociales como generadores de empleo.

\section{MuestRA, FUENTES DE INFORMACIÓN Y METOdOLOGÍA}

\section{Muestra}

La muestra objeto de estudio está constituida por el universo de centros de atención a la dependencia de la región de Cantabria (incluyendo tanto la atención a mayores como a discapacitados). De acuerdo con la información suministrada por la Dirección General de Políticas Sociales del Gobierno de Cantabria, en la Comunidad Autónoma existen un total de 144 centros concertados ${ }^{7}$ de atención a la dependencia, que se elevan a 152 si se incluyen los no concertados. El total de plazas autorizadas asciende a 8.544 , de las que el $64 \%$ son plazas en residencias para mayores y un $14 \%$ son plazas en centros de día para mayores, de manera que el $78 \%$ de las plazas están vinculadas con personas mayores. La tabla 3 describe la muestra objeto de estudio.

\footnotetext{
${ }^{7}$ Se excluyen del análisis las 8 viviendas tuteladas que existen en la región para mayores y discapacitados, concertadas con un total de 83 plazas, puesto que su impacto económico puede considerarse prácticamente nulo.
} 
Tabla 3.

Muestra objeto de estudio.

\begin{tabular}{lccccc}
\hline Centros & $\begin{array}{c}\mathrm{n}^{\circ}{ }^{0} \\
\text { centros }\end{array}$ & $\begin{array}{c}\mathrm{n}^{\circ}{ }^{\circ} \text { centros } \\
\text { concertados }\end{array}$ & $\begin{array}{c}\text { plazas } \\
\text { autorizadas }\end{array}$ & $\begin{array}{c}\% \text { plazas } \\
\text { autorizadas }\end{array}$ & $\begin{array}{c}\text { plazas } \\
\text { concertadas }\end{array}$ \\
\hline Residencias para Personas Mayores & 58 & 52 & 5.439 & $64 \%$ & 3.570 \\
Centro de Día para Personas Mayores & 46 & 44 & 1.190 & $14 \%$ & 1.064 \\
Residencias 24h Personas con Discapacidad & 6 & 6 & 494 & $6 \%$ & 451 \\
Residencia Atención Básica Discapacidad & 8 & 8 & 214 & $3 \%$ & 206 \\
Centro de Día Personas con Discapacidad & 15 & 15 & 347 & $4 \%$ & 342 \\
Centro Ocupacional Pers. Discapacidad & 12 & 12 & 537 & $6 \%$ & 494 \\
Centro Rehabilitación Psicosocial & 7 & 7 & 323 & $4 \%$ & 299 \\
\hline Total & 152 & 144 & 8.544 & $100 \%$ & 6.426 \\
\hline
\end{tabular}

Fuente: Elaboración propia, a partir de la información suministrada por la Dirección General de Políticas Sociales del Gobierno de Cantabria.

\section{Fuentes de información}

Para realizar el análisis empírico que permita cuantificar el impacto económico de la atención a la dependencia se utilizan las siguientes fuentes de información:

Análisis de la normativa vigente sobre la atención de personas en situación de dependencia, en relación con los requisitos de personal mínimo en estos centros, así como los convenios colectivos que regulan las retribuciones.

Fuente de información primaria que se obtiene mediante cuestionario a los centros de atención a la dependencia, con el ánimo de recabar información cuantitativa e individualizada de todos los centros en cuanto a número de trabajadores, generación de beneficios, retribuciones o pago de impuestos ${ }^{8}$. Los cuestionarios se realizaron durante el primer semestre de 2010 y se dirigieron a los responsables de los centros. El coeficiente de respuesta fue de un $93,42 \%$ con un total de 142 respuestas, lo que permite extrapolar los resultados al resto de la población y tener una fuente primaria real de información sobre la que apoyar el análisis de impacto económico.

Las tablas input-output calculadas para Cantabria por el Instituto Cántabro de Estadística (ICANE) y publicadas en 2010, y en particular la matriz inversa de Leontief interior que refleja

\footnotetext{
${ }^{8}$ Tanto en España como en Cantabria se carece de una base de datos que centralice este tipo de información. La información que algunos de estos centros presentan en los registros oficiales tampoco resulta válida para el estudio, puesto que las grandes organizaciones pueden prestar servicios distintos (aparte de la atención a la dependencia) pero presentan la información conjunta de la organización.
} 
54 ramas de actividad y que permite relacionar incrementos en la producción con incrementos en la demanda final, como se explicará en la metodología. Esta fuente secundaria de información se aplicará en el cálculo del efecto de los centros de atención a la dependencia sobre la producción, el empleo, los impuestos y la recaudación de la Seguridad Social

Como fuente de información secundaria también se accede a información sobre recaudación suministrada por la Hacienda Pública para el cálculo del efecto sobre los impuestos.

\section{Metodología}

El impacto económico que produce una actividad puede desagregarse en tres componentes: directo, indirecto e inducido, como se señala en el gráfico 2. Este estudio analizará los tres impactos, de manera que se puedan extraer conclusiones sobre el impacto económico total de la atención a la dependencia.

Gráfico 2.

Desagregación del impacto económico.

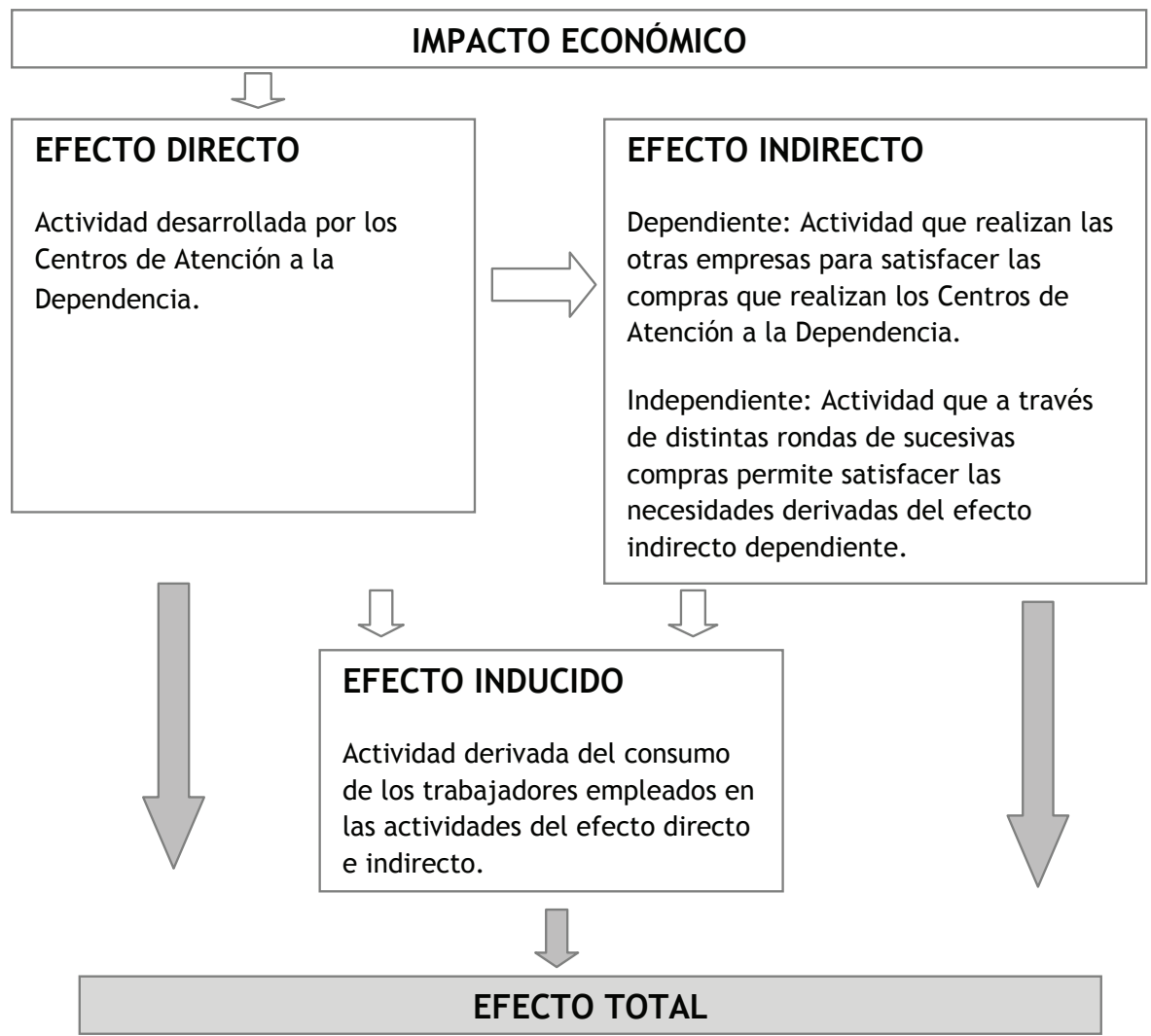




\section{Efecto directo}

Para cuantificar el impacto directo es preciso conocer de qué manera los centros de atención a la dependencia están afectando al empleo, y cuáles son las retribuciones que reparten y los beneficios que generan, para poder cuantificar el efecto sobre los impuestos (IS e IRPF) y la Seguridad Social.

Para el cálculo del efecto directo sobre los impuestos y la Seguridad Social que tiene la atención a la dependencia se plantean las siguientes premisas:

1. "Seguridad Social". Se calcula a partir de la información de las tablas input-output teniendo en cuenta el porcentaje que las aportaciones a la Seguridad Social representan sobre los sueldos y salarios en la rama de actividad 50 (Servicios sociales), que asciende a $28,23 \%$ e incluye las cotizaciones sociales a cargo de la empresa. Para la cotización a cargo del trabajador se han calculado las cotizaciones utilizando los tipos de cotización legalmente establecidos sobre los pagos salariales. El tipo aplicado ha sido 6,35\%.

2. "IRPF". A partir de los datos de recaudación de Cantabria proporcionados por el ICANE, se ha calculado el tipo medio global. En Cantabria este valor es $22,72 \%$.

3. La recaudación por "IVA" y otros impuestos sobre la producción se calcula también a partir de la información de las tablas input-output.

4. Para el cálculo del impacto en el "Impuesto de Sociedades" de los centros de atención a la dependencia se ha definido el tipo efectivo global como el cociente entre la cuota líquida recaudada en Cantabria y el valor añadido total generado. El tipo efectivo en el caso de Cantabria adopta un valor del 20,32 \% ${ }^{10}$. Este tipo se aplica sobre el beneficio.

\section{Efecto indirecto e inducido}

Para estimar tanto el impacto indirecto como inducido, será preciso hacer uso de la metodología propuesta por Leontief (1986), mediante la utilización de las tablas input-

\footnotetext{
9 El tipo medio global calculado en estudios previos asciende a valores de 18,02 \% (Centro de Documentación y Estudios de la Fundación Eguía Careaga, SIIS 1994), 15,94 \% (Federación Vasca de Asociaciones a favor de las Personas con Discapacidad Intelectual o del Desarrollo 2007) y 17,62 \% (Zubiri 2010).

10 La diferencia entre el tipo nominal (que legalmente en Cantabria es del $30 \%$ ) y el tipo efectivo (impuesto pagado/beneficios) radica en los incentivos y bonificaciones que se produzcan. El 20,32 \% considerado resulta prudente, ya que en aquellos casos en los que se ha tenido información individualizada de los centros se ha observado un tanto efectivo que oscila entre el $22 \%$ y el $28 \%$.
} 
output ${ }^{11}$. Para el cálculo del "efecto indirecto" se procederá de acuerdo con las siguientes etapas:

1. Estimación de las compras e inversiones que se realizan en un año por parte de los centros de atención a la dependencia en los distintos sectores. Esta información se obtiene mediante el cuestionario antes mencionado.

2. Utilización de las tablas input-output, y en particular de la matriz inversa de Leontief interior que refleja 54 ramas de actividad. La matriz inversa de Leontief permite relacionar incrementos en la producción con incrementos en la demanda final, de la siguiente manera:

$X=(I-A)^{-1} * Y$, donde

$Y=$ Vector de demanda final (rango $n * 1$ ). Vector que recoge los incrementos de demanda final, derivados de las compras e inversiones que realizan los centros de atención a la dependencia en otros sectores.

$\mathrm{n}=$ número de ramas de actividad (en este estudio son 54).

$\mathrm{X}=$ Vector columna de la producción efectiva a salida de fábrica (rango $\mathrm{n}^{*} 1$ ). Recoge la producción de cada uno de los sectores, originada como consecuencia del incremento de demanda final.

$(\mathrm{I}-\mathrm{A})^{-1}=$ Matriz inversa de Leontief.

I = Matriz identidad (rango $\left.n^{*} n\right)$. Matriz identidad, compuesta por 1 en su diagonal principal y por 0 en el resto de elementos.

$A=$ Matriz de coeficientes verticales (rango $n^{*} n$ ). Matriz que contiene las relaciones entre la producción intermedia interior y la producción efectiva a salida de fábrica para cada sector de actividad.

3. Los incrementos en la producción efectiva $(X)$ pueden transformarse en incrementos en distintas macromagnitudes económicas, utilizando la información disponible en las tablas input-output. En particular, se analizará el impacto sobre los siguientes aspectos de la actividad económica:

a) Número de puestos de trabajo.

b) Remuneración de los asalariados.

c) Producción.

d) Impuestos y Seguridad Social.

Para la estimación del "efecto inducido", se procederá de la siguiente manera:

${ }^{11}$ Otros estudios, como el de Dutrénit (2005), han aplicado la metodología del análisis coste-beneficio para analizar la atención a mayores. Sin embargo, el análisis coste-beneficio no permitiría cuantificar el impacto económico de dicha atención. Por su parte, Fontela (2004) pone de manifiesto la importancia de la metodología de Leontief para valorar el impacto económico de diferentes sectores. 
1. Cálculo del consumo privado que se deriva de las retribuciones de los trabajadores (tanto del efecto directo como del indirecto), una vez descontadas las aportaciones a la Seguridad Social y el IRPF.

$\left.\underline{\begin{array}{l}\text { Consumo } \\ \text { privado }\end{array}=\left(\begin{array}{c}\text { Retribución asalariados } \\ \text { efecto directo }\end{array}\right.}+\begin{array}{c}\text { Retribución asalariados } \\ \text { efecto indirecto }\end{array}\right) * \begin{gathered}\text { Coeficiente de } \\ \text { consumo privado }\end{gathered}$

* El coeficiente de consumo privado se extrae de la Encuesta de Presupuestos Familiares del Instituto Nacional de Estadística de España y asciende a $75 \%$.

2. Se calcula la estructura de consumo por sectores a partir de la tabla inputoutput.

3. Se utiliza de nuevo la matriz inversa de Leontief, que permite relacionar incrementos en la demanda final derivados del mayor consumo con incrementos en la producción, utilizando la expresión: $X=(I-A)^{-1}$ * $Y$, donde $Y$ es el vector que recoge dicho incremento en la demanda final derivado de un mayor consumo.

4. De nuevo, los incrementos en la producción efectiva $(X)$ derivados del efecto inducido se descomponen en incrementos en distintas macromagnitudes económicas: puestos de trabajo, retribuciones, producción, impuestos y Seguridad Social.

En particular, el cálculo del impacto recaudatorio indirecto e inducido del sector de la atención a la dependencia se ha realizado de la siguiente forma:

1. La "aportación a la Seguridad Social" se obtiene mediante las tablas input-output, así como las aportaciones al "IVA y otros impuestos sobre la producción".

2. "IRPF". Para calcular el impacto indirecto e inducido sobre el IRPF, el tipo medio global se ha multiplicado por los sueldos y salarios brutos obtenidos a través de las tablas input-output para el efecto indirecto e inducido.

3. "Impuesto de Sociedades". El tipo efectivo global'12 se ha multiplicado por el valor añadido obtenido a través de las tablas input-output para el efecto indirecto e inducido.

\section{RESULTADOS DEL IMPACTO DIRECTO DE LA ATENCIÓN A LA DEPENDENCIA}

Los resultados sobre el impacto directo se presentan en el siguiente orden. En primer lugar, se muestra el impacto sobre el empleo. En segundo lugar, se reflejan las retribuciones del personal directo contratado en atención a la dependencia (que tendrán su impacto económico vía IRPF y Seguridad Social). En tercer lugar, se estiman los beneficios de los centros de atención a la dependencia (que tendrán su impacto económico vía

\footnotetext{
${ }^{12}$ Definido como el cociente entre la cuota líquida recaudada en Cantabria y el valor añadido total generado.
} 
IS). Las retribuciones y los beneficios permitirán calcular el efecto sobre la recaudación y las aportaciones a la Seguridad Social, cuyos resultados se han incluido junto con los del impacto indirecto e inducido. En cuarto lugar, se calcula el ahorro en prestaciones por desempleo a que puede dar lugar el empleo creado por la atención a la dependencia, y que supondrá un incremento de la cantidad que revierte a la Administración por su inversión en atención a la dependencia.

\section{Impacto directo sobre el empleo en Cantabria: hipótesis de cálculo y resultados}

La información recogida a través de cuestionario sobre el número de trabajadores de cada centro presenta dificultades para poder emitir una conclusión sobre el efecto directo que esta actividad tiene sobre el empleo por los siguientes motivos: 1) existe personal contratado con diferentes jornadas laborales -lo que obliga a calcular el número de empleos equivalentes a jornada completa para poder homogeneizar el impacto-, 2) los centros pueden compartir personal, de manera que la misma persona presta sus servicios en distintos centros, lo que podría dar lugar a duplicidades en el cálculo del impacto sobre el empleo, 3) existe disparidad en los ratios de personal de los centros (centros de la misma tipología presentan diferentes empleados por usuario, cuando la normativa exige unos ratios mínimos).

Dadas estas limitaciones y siendo prudentes en la estimación, se acude a la normativa que regula las necesidades mínimas de personal de los centros de atención a personas en situación de dependencia. En particular, la Orden EMP/37/2010, de 18 de marzo, recoge en su artículo 15 las necesidades mínimas de personal referidas a 100 personas usuarias de los centros de atención a la dependencia para Cantabria. Por lo tanto, el impacto sobre el empleo que se obtenga aplicando la citada Orden tendrá carácter de mínimo.

La Orden EMP/37/2010 establece las siguientes necesidades de personal:

1. Directores/as de los centros. Todos los centros deberán contar con una persona que ejerza las tareas de dirección. En el caso de que haya varios centros de atención a personas en situación de dependencia con la misma titularidad, y que se encuentren ubicados en un mismo edificio o en edificios colindantes, podrá ejercer las funciones de dirección de aquellos una misma persona. En este supuesto, cuando el número total de plazas sea igual o menor de sesenta, la persona que ejerza la dirección podrá ser un miembro del equipo de atención directa.

2. Personal de atención directa. La Orden establece el número de horas de prestación de servicios en función de los 14 tipos de centro que distingue, y diferenciando entre las horas ocupadas por técnicos y por titulados universitarios ${ }^{13}$.

\footnotetext{
${ }^{13}$ Véase la Orden EMP/37/2010 de 18 de marzo para el detalle del número de horas exigido para la prestación del servicio.
} 
3. Personal de atención indirecta. Las tareas de cocina, limpieza, lavandería, mantenimiento, administración y recepción se podrán prestar por personal del centro o mediante contrato con empresas prestadoras de servicios. En cualquier caso, la prestación diaria de servicios de este personal no será inferior a 10 horas en los centros residenciales y a 7 horas en los centros de atención diurna, por cada 100 personas usuarias, con un mínimo en ambos casos de 2 horas diarias.

Asimismo, para la estimación del impacto de la atención a la dependencia sobre el empleo se han tenido en cuenta las siguientes hipótesis de cálculo:

- Para los centros residenciales se considera su funcionamiento durante los 365 días del año, mientras que para los centros de día, ocupacionales o de rehabilitación psicosocial se ha estimado un funcionamiento de lunes a viernes, 0261 días al año.

- Para centros de mayores se considera una jornada máxima de 1792 horas al año, de acuerdo al V Convenio Colectivo Marco Estatal de Servicios de Atención a las Personas Dependientes y Desarrollo de la Promoción de la Autonomía Personal (Boletín Oficial del Estado 1/4/2008). Para centros de atención a la discapacidad se considera una jornada máxima de 1729 horas al año, de acuerdo al XIII Convenio Colectivo General de Centros y Servicios de Atención a Personas con Discapacidad (Boletín Oficial del Estado 16/8/2010).

Con estas premisas, los resultados sobre necesidades de personal en los centros de atención a la dependencia se recogen en la Tabla 4.

Los 2.978 empleos directamente vinculados al sector de atención a la dependencia (sin incluir el personal vinculado a las 83 plazas en viviendas tuteladas para personas mayores 0 para dependientes) suponen el 1,23 \% de la población ocupada en Cantabria en junio de 2010.

Además del personal vinculado directamente a los centros de atención a la dependencia, la prestación del Servicio de Ayuda a Domicilio (SAD) y la Teleasistencia (TAD) suponen también un impacto importante sobre el empleo.

En particular, los datos a diciembre de 2010 muestran un total de 55.954 horas destinadas al SAD para un total de 1.100 usuarios. Los usuarios de TAD ascendieron a 590. Para calcular el efecto sobre el empleo en ambos servicios se han supuesto las siguientes hipótesis:

1. En el caso del $S A D$, se calcula el número de trabajadores equivalentes a jornada completa, considerando como jornada la establecida en el XIII Convenio de Discapacidad (1.729 horas) y que el número de horas empleadas en el mes de diciembre es similar al demandado en el resto de meses del año (55.954 horas/ mes). El número total de trabajadores a jornada completa del SAD es de $388^{14}$.

\footnotetext{
${ }^{14}$ Desde el 1 de enero de 2011 estos trabajadores están sujetos al V Convenio Marco Estatal de Dependencia, en el que la jornada máxima asciende a 1.792 horas.
} 
Tabla 4.

Necesidades de personal de acuerdo con la Orden EMP/37/2010 de 18 de marzo.

\begin{tabular}{|c|c|c|c|c|c|c|}
\hline Centros & $\begin{array}{c}\text { Plazas } \\
\text { Autorizadas }\end{array}$ & $\begin{array}{l}\text { Personal } \\
\text { de Atención } \\
\text { Directa }\end{array}$ & $\begin{array}{l}\text { Personal } \\
\text { Indirecto* }\end{array}$ & TOTAL & $\begin{array}{l}\text { Ratio de } \\
\text { Atención } \\
\text { Directa" }\end{array}$ & $\begin{array}{l}\text { Ratio de } \\
\text { Personal }{ }^{+*}\end{array}$ \\
\hline Residencias para Personas Mayores & 5.439 & 2.023 & 142 & 2.165 & 0,37 & 0,40 \\
\hline Centro de Día para Personas Mayores & 1.190 & 225 & 17 & 242 & 0,19 & 0,20 \\
\hline Residencias 24h Personas con Discapacidad & 494 & 225 & 14 & 239 & 0,46 & 0,48 \\
\hline Residencia Atención Básica Discapacidad & 214 & 62 & 6 & 68 & 0,29 & 0,32 \\
\hline Centro de Día Personas con Discapacidad & 347 & 108 & 6 & 114 & 0,31 & 0,33 \\
\hline Centro Ocupacional Personas Discapacidad & 537 & 81 & 9 & 90 & 0,15 & 0,17 \\
\hline Centro Rehabilitación Psicosocial & 323 & 52 & 7 & 59 & 0,16 & 0,18 \\
\hline TOTAL & 8.544 & 2.776 & 202 & 2.978 & 0,32 & 0,35 \\
\hline
\end{tabular}

* Incluye a los directores cuando no son miembros del personal de atención directa

${ }^{* *}$ Ratio de atención directa $=$ Personal de atención directa/usuarios.

*** Ratio de personal $=$ Personal de atención directa e indirecta/usuarios.

Fuente: Elaboración propia.

2. En el caso del personal vinculado al $T A D$, se considera el ratio de personal que figura en el Libro blanco, según el cual existiría un trabajador por cada 100 usuarios. Dado que los usuarios ascendieron a 590 personas, se podría establecer una necesidad de personal de 6 trabajadores.

Por lo tanto, el efecto total sobre el empleo asciende a 3372 trabajadores (incluyendo SAD y TAD), lo que supone el 1,39 \% de la población ocupada en Cantabria.

\section{Retribuciones del personal asociado a los centros de atención a la dependencia en Cantabria: hipótesis de cálculo y resultados}

En Cantabria, los resultados obtenidos del cuestionario en cuanto a retribuciones plantean los mismos problemas que en el caso del número de trabajadores, por lo que ha sido necesario acudir a lo establecido en los convenios colectivos correspondientes para realizar el cálculo del impacto directo de los centros de atención a la dependencia en las retribuciones, estableciendo las siguientes hipótesis:

- Para centros de mayores la tabla salarial correspondiente al año 2010 del Convenio Colectivo Marco Estatal de Servicios de Atención a las Personas Depen- 
dientes y Desarrollo de la Promoción de la Autonomía Personal (Boletín Oficial del Estado 1/3/2010). Para centros de atención a la discapacidad se aplica la tabla salarial del XIII Convenio Colectivo General de Centros y Servicios de Atención a Personas con Discapacidad (Boletín Oficial del Estado 16/8/2010).

- La retribución se calcula a partir de las doce pagas ordinarias del salario base, más el plus de antigüedad, más dos pagas extraordinarias del mismo importe.

- Se ha establecido la siguiente estructura de personal universitario: $10 \%$ con categoría de médicos o titulados superiores, $60 \%$ con categoría de ATS/DUE, $30 \%$ con categoría de fisoterapeuta o trabajador social, tanto en centros de mayores como de dependientes, de acuerdo con los resultados medios observados en el cuestionario realizado.

- Se establece un plus por festivos, domingos y nocturnidad de acuerdo con el convenio aplicable a cada centro.

- Se establece un plus por antigüedad del $5 \%$ del sueldo base. Ante la imposibilidad de poder determinar la antigüedad exacta de cada trabajador y el plus que le correspondería, se establece el $5 \%$ por término medio siguiendo el estudio de Deloitte (2006). Este $5 \%$ resulta coherente con los resultados obtenidos del cuestionario a los directores de los centros, en el que se preguntaba qué porcentaje representaban los gastos adicionales de personal sobre el salario base, incluyendo antigüedad, nocturnidad, plus de festivos, prevención de riesgos, sustituciones o formación. Una vez eliminados los valores extremos, los costes adicionales de personal representaban por término medio el 10,10\%. Se ha sido prudente en la estimación de los costes adicionales de personal, puesto que en este estudio únicamente se consideran dos costes adicionales: $5 \%$ para la antigüedad y $3,3 \%$ por término medio de complementos derivados de festivos y nocturnidad, de acuerdo con los convenios colectivos. El resultado de esta prudencia sería una infravaloración del impacto económico obtenido. De hecho, Deloitte (ibídem) añade al coste de personal un coste adicional solo por sustituciones del $6 \%$ y Codorniu (2005) del $8 \%$.

Los resultados muestran una retribución total de 51.878 .605 euros al año distribuida entre el personal de los centros de atención a la dependencia sin incluir las viviendas tuteladas. A esta cantidad habría que añadir dos partidas adicionales de retribución:

1. El coste de personal derivado del Programa de Atención a Personas Dependientes, recogido en la tabla 2 y que asciende a 25.114 .932 euros en $2010^{15}$.

${ }^{15}$ De esta cantidad se descuenta el pago a la Seguridad Social por parte de la empresa y la retribución de 4.555.777,6 euros que se corresponde con la calculada para los centros de atención a la dependencia del Gobierno y que estaría incluida dentro de la retribución calculada anteriormente de 51.878 .605 euros Por lo tanto, el salario bruto ascendería a 14.778 .273 euros. 


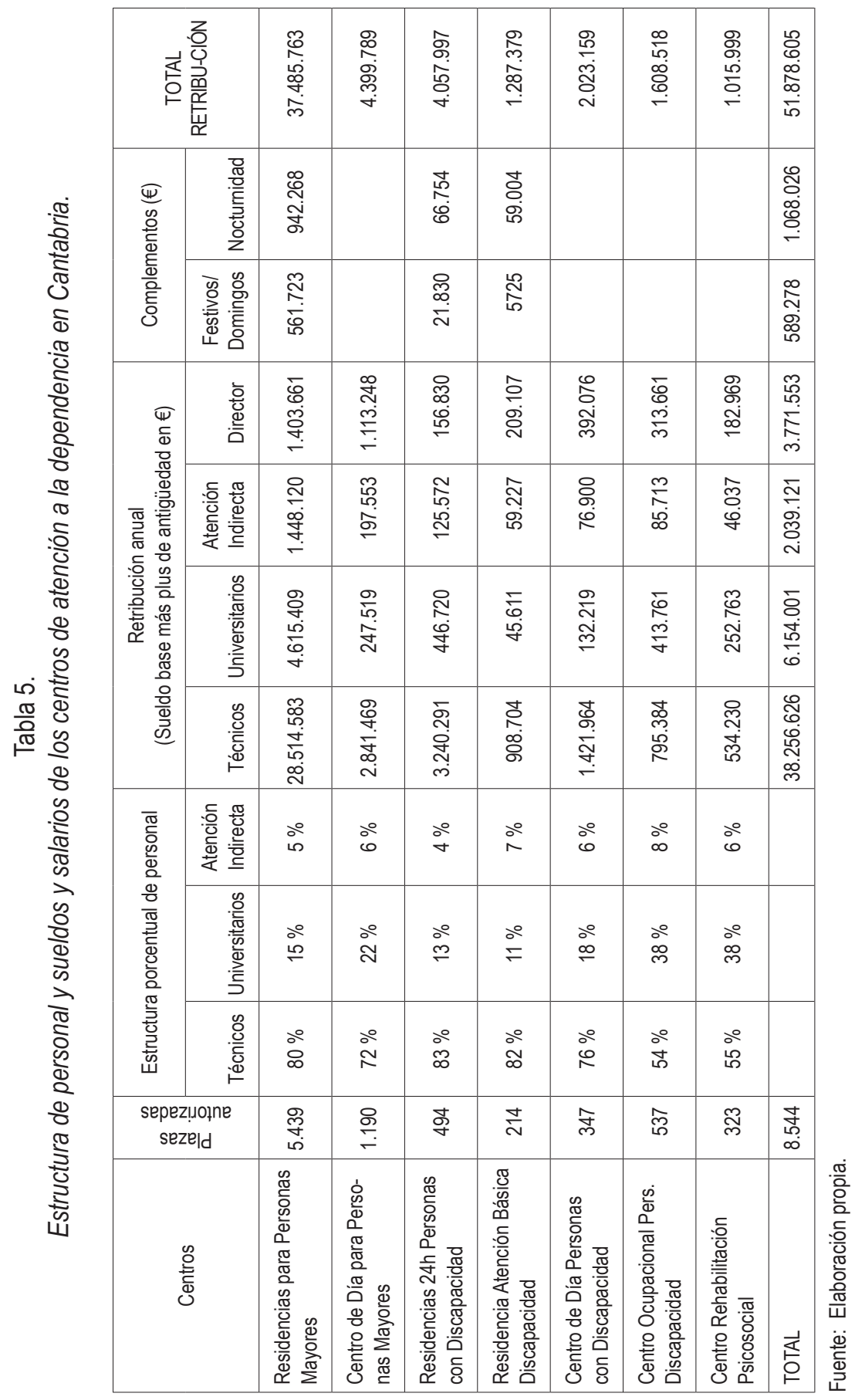


2. La retribución recibida por los 388 trabajadores del SAD. Esta retribución se establece en función del XIII Convenio Colectivo General de Centros y Servicios de Atención a Personas con Discapacidad, siendo el salario base mensual en 2010 en la categoría de cuidador o auxiliar de enfermería de 876,23 euros. Considerando un total de 14 pagas y un $5 \%$ adicional por antigüedad, la retribución se eleva a 4.997.665,4 euros.

Tabla 6.

Impacto directo de la atención a la dependencia sobre la retribución.

\begin{tabular}{lc}
\hline Retribución & Cuantía \\
\hline De los Centros de Atención a la Dependencia & 51.878 .605 \\
Del Programa de Atención a Personas Dependientes & 14.778 .273 \\
Del personal del SAD & 4.997 .665 \\
TOTAL & 71.654 .543
\end{tabular}

Fuente: Elaboración propia.

Estimación de los beneficios de los centros de atención a la dependencia: hipótesis de cálculo y resultados

Para poder realizar una estimación de los beneficios generados por los centros de atención a la dependencia, con el objetivo de valorar su impacto en la recaudación, se parte de los datos de margen de beneficios ${ }^{16}$ y costes asociados a los centros extraídos de la información suministrada a través del cuestionario.

$$
\text { Beneficio }=\text { Margen }{ }^{*} \text { Costes }
$$

En relación con el margen de beneficios, se establecerán tres niveles de márgenes en función del tamaño del centro:

- $3 \%$ para centros con menos de 50 plazas. El $69 \%$ de los centros encuestados con menos de 50 plazas afirmaron tener una rentabilidad inferior al $5 \%$ o pérdidas. Los centros con pérdidas son en general gestionados por fundaciones, asociaciones de las fundaciones sin fines lucrativos y asociaciones declaradas de utilidad pública, y por lo tanto están exentas del pago de impuesto de sociedades de acuerdo con el

${ }^{16} \mathrm{El}$ margen se calcula a través del ratio beneficio/costes e indica qué porcentaje de los costes se convierte en beneficio. 
artículo 7 de la Ley 49/2002 de 23 de diciembre de Régimen Fiscal de la Entidades Sin Fines Lucrativos y de los Incentivos Fiscales al Mecenazgo ${ }^{17}$.

- $7 \%$ para centros entre 50 y 100 plazas al igual que en los trabajos realizados por Deloitte (2006) y el Centro Europeo de Empresas e Innovación de Navarra, CEIN (2003). Este valor guarda coherencia con los resultados del cuestionario, puesto que el $50 \%$ de estos centros afirmaron tener un margen rondando el $5 \%$ y el $35,7 \%$ entre el $6 \%$ y el $15 \%$.

- $10 \%$ para centros con más de 100 plazas. Un valor intermedio entre $8 \%$ y $12 \%$, que es lo observado en el estudio $\mathrm{BIC}$ (2008) y que responde a lo observado en el cuestionario para Cantabria en el que el $58,3 \%$ de centros con más de 100 plazas afirmaron tener márgenes entre el $6 \%$ y el $15 \%$.

En relación con los costes, el análisis se basa en el coste/plaza/día de la atención a la dependencia estableciendo también 3 niveles de tamaño de los centros. La información sobre el coste/plaza/día se obtiene de los resultados del cuestionario a los centros ${ }^{18}$, según los cuales el coste oscila entre 31,79 euros en centros de atención diurna con más de 100 usuarios y 61,43 euros en centros de atención residencial con menos de 50 usuarios. Teniendo en cuenta a los centros de atención a la dependencia de Cantabria y estos costes por plaza y día, se estima un coste total anual de 161.318.154,25 euros.

Finalmente, teniendo en cuenta la información sobre el margen y los costes se obtiene el beneficio de estos centros, que asciende a cerca de 12 millones de euros ${ }^{19}$ de los que 8.007.896,04 se consideran como beneficio exento ${ }^{20}$ (sin incluir el posible beneficio que se deriva del $S A D^{21}$ ), como muestra la Tabla 7.

${ }^{17}$ No se considera, por lo tanto, un nivel de margen negativo en centros con menos de 50 plazas,
puesto que estos son excluidos a la hora de computar los impuestos, al ser gestionados por fundaciones,
asociaciones de las fundaciones sin fines lucrativos y asociaciones declaradas de utilidad pública. En caso de
observarse margen negativo en un centro gestionado con fines lucrativos la situación resultaría insostenible
en el tiempo y por lo tanto sería necesario sustituir la gestión por otra más eficiente.
\begin{tabular}{lccc}
${ }^{18}$ Se obtienen los siguientes valores de coste/plaza/día (en euros): & \\
\hline \multicolumn{5}{c}{ Menos de 50 usuarios } & Entre 50 y 100 usuarios & Más de 100 usuarios \\
\hline Atención diurna & 33,32 & 32,27 & 31,79 \\
\hline Atención residencial & 61,43 & 59,52 & 58,42
\end{tabular}

${ }^{19}$ Concretamente $11.851 .838,31$ euros.

${ }^{20}$ Se denomina 'beneficio exento' al obtenido por centros cuya explotación económica está exenta del impuesto de sociedades, y que por lo tanto no habrá que considerar en el cálculo de dicho impuesto. De acuerdo con el artículo 7 de la Ley 49/2002 de 23 de diciembre de Régimen Fiscal de la Entidades Sin Fines Lucrativos y de los Incentivos Fiscales al Mecenazgo, se consideran explotaciones económicas exentas del Impuesto de Sociedades la asistencia a la tercera edad y la asistencia a personas con discapacidad realizada por fundaciones, asociaciones de las fundaciones sin fines lucrativos y asociaciones declaradas de utilidad pública.

${ }^{21}$ Atendiendo a la información proporcionada por la Dirección General de Política Social, del presupuesto 
Tabla 7.

Impacto directo de la atención a la dependencia sobre los beneficios y costes asumidos por los centros.

\begin{tabular}{ccccccc}
\hline & $\begin{array}{c}\text { Plazas } \\
\text { autorizadas }\end{array}$ & $\begin{array}{c}\text { Plazas } \\
\text { exentas }\end{array}$ & $\begin{array}{c}\text { \% plazas } \\
\text { exentas }\end{array}$ & Costes & Beneficios & $\begin{array}{c}\text { Beneficio } \\
\text { exento }\end{array}$ \\
\hline TOTAL & 8544 & 5853 & $69 \%$ & $161.318 .154,25$ & $11.851 .838,31$ & $8.007 .896,04$ \\
\hline
\end{tabular}

* Se denomina "plaza exenta" a aquella que pertenece a un centro cuya explotación económica está exenta del impuesto de sociedades.

Fuente: Elaboración propia.

\section{Ahorro en prestaciones por desempleo}

El sector de la atención a la dependencia, al ser intensivo en mano de obra y generar empleo, permitiría el ahorro en prestaciones por desempleo de aquellas personas que como consecuencia de la potenciación del sector dejarían de estar desempleadas.

Dado que a priori no somos capaces de determinar con exactitud el número de personas que estando paradas son ocupadas en el sector y por lo tanto permiten este ahorro, se han considerado una serie de hipótesis para su estimación que, como se comprueba en la tabla 8, permiten establecer unos ahorros mínimos por este concepto:

- Prestación mínima por desempleo de 664,75 euros al mes².

- Se descuenta de esta cantidad lo que revierte a la Administración vía retenciones del IRPF y pago a la Seguridad Social a cargo del trabajador por contingencias comunes.

- Se aplica una tasa de desempleo del 14,5\%, según los últimos datos, correspondientes a 2009, publicados por el ICANE.

El ahorro en prestaciones por desempleo asciende en Cantabria a más de 3 millones de euros equivalente a 929 euros anuales por empleo generado en el sector de atención a la dependencia. Esta cantidad es similar a la observada para España en el Libro blanco (2004), pero resulta muy inferior a la observada en la región de Valencia, ya que en este último estudio se consideraba como hipótesis que el $100 \%$ de los trabajadores del sector de atención a la dependencia estarían recibiendo prestación por desempleo en caso de no existir el sector.

destinado al SAD que asciende a 9,1 millones de euros, el 7\% aproximadamente sería beneficio empresarial (es decir 637.000 euros de beneficio). Sin embargo, dependiendo de la titularidad jurídica de quien gestione el SAD la tributación puede cambiar por lo que a efectos de cálculo en este trabajo se suprime su impacto.

${ }^{22}$ Cuantía mínima establecida legalmente para 2010 para personas con un hijo. La cuantía mínima sin hijos sería de 497 euros/mes y las máximas de 1087,20; 1242,52 (con un hijo) y 1397,83 (con dos hijos). 
Tabla 8.

Ahorro en prestaciones por desempleo.

\begin{tabular}{lccc}
\hline Ámbito & España & Comunidad & Valenciana \\
\hline Referencia & Libro blanco de la & FED & Cantabria \\
Ahorro en prestaciones por desempleo & 404.000 .000 & 31.100 .000 & propián \\
Generación de empleos & 352.235 & 3.080 & $3.131 .920,33$ \\
Ahorro por empleo generado & $1.146,96$ & $10.097,40$ & 9.372 \\
\hline
\end{tabular}

Fuente: Elaboración propia.

\section{EFECTO INDIRECTO Y EFECTO INDUCIDO}

Una vez cuantificado el efecto directo, resulta necesario pasar a analizar los efectos económicos indirectos e inducidos de la atención a la dependencia. La demanda de bienes y servicios que las empresas del sector de atención a la dependencia realizan de otros sectores tendrá un efecto indirecto sobre la producción y el empleo. Asimismo, el consumo privado que realizan los trabajadores tanto de la actividad directa como de la indirecta, producirá toda una nueva cadena de demanda con su efecto sobre la producción y el empleo, lo que constituye el efecto inducido.

\section{Estimación de las compras e inversiones de los centros de atención a la depen- dencia en los distintos sectores y el efecto indirecto}

Los gastos realizados por los centros de atención a la dependencia ascienden a 161.318.154,25 euros, tal y como se comentó anteriormente ${ }^{23}$. Para establecer el reparto de dicho gasto entre los diferentes sectores se ha utilizado la estructura de gastos que se desprende de los resultados obtenidos del cuestionario realizado a los centros de atención a la dependencia de Cantabria. De este importe total se eliminan una serie de partidas que no son atribuidos a gastos 0 inversiones en ningún sector, como son los costes salariales ${ }^{24}$, la amortización de los inmuebles o los gastos financieros. De esta manera, el gasto o inversión de estos centros que se puede asignar a otros sectores

\footnotetext{
${ }^{23}$ No se incluye en este caso el gasto realizado en otros sectores por el SAD, ya que su impacto es mínimo. De los 9,1 millones destinados al SAD, la mayoría se asigna a retribuciones, por lo que queda una mínima cuantía para gastos de material.

${ }^{24} \mathrm{El}$ impacto económico directo de los costes salariales de los centros de atención a la dependencia se cuantifica posteriormente al calcular su impacto en la recaudación.
} 
asciende a más de 54 millones de euros. La división de dicho gasto por sectores se recoge en la tabla $9^{25}$.

Tabla 9.

Distribución del gasto de los centros de atención a la dependencia por ramas de actividad.

\begin{tabular}{lccc}
\hline & $\begin{array}{c}\text { Estructura } \\
\text { porcentual del coste } \\
(\%)\end{array}$ & $\begin{array}{c}\text { Rama } \\
\text { de actividad CNAE } \\
2009\end{array}$ & $\begin{array}{c}\text { Rama de actividad } \\
\text { Marco input-output } \\
\text { Cantabria }\end{array}$ \\
\hline Coste equipamiento & 6,9 & 26 & 19 \\
Coste de manutención & 42,58 & 56 & 34 \\
Coste de mantenimiento y suministro & 14,73 & 35 & 24 \\
Coste de limpieza & 8,33 & 81 & 46 \\
Coste en seguros y seguridad & 1,8 & 65 & 39 \\
Coste en viajes y traslados & 1,43 & 49 & 31 \\
Servicios de gestión & 24,23 & 82 & 46 \\
\hline
\end{tabular}

Fuente: Elaboración propia.

La aplicación de la metodología de las tablas input-output permite extraer los principales valores de la magnitudes macroeconómicas que señalan un impacto sobre el PIB de 73,4 millones de euros y una generación de empleo de 889 trabajadores con una retribución bruta de 15,6 millones de euros.

\section{Efecto inducido}

Para el cálculo del efecto inducido se estima en primer lugar el potencial de consumo familiar a partir de los datos de salarios brutos, obtenidos de la actividad directa de atención a la dependencia (71.654.543 euros), así como a partir de los salarios brutos que originaba la actividad indirecta de la atención a la dependencia en otros sectores, que fue estimada mediante las tablas input-output y que ascendía a 15.602.784,19 euros. Aplicando un coeficiente de consumo privado del $75 \%$, una vez descontada la cotización a la Seguridad Social y el IRPF, el consumo familiar asciende a 46.583.969,7 euros. Asimismo, se agrega a este potencial de consumo

\footnotetext{
${ }^{25}$ Se considera la distribución porcentual media del coste de los centros de atención a la dependencia en cada sector, independientemente de la tipología de centro, de manera que se pueda cuantificar el impacto económico global de la atención a la dependencia.
} 
el derivado de las Prestaciones del Sistema para la Autonomía y Atención a Personas Dependientes concedidas por el Gobierno de Cantabria y que ascienden a 20.000.000 euros como se señaló en la Tabla 2. De esta manera, el potencial de consumo total asciende a 61.583.969,7 euros.

El consumo se distribuye entre las 54 ramas de actividad que figuran en las tablas input-output de acuerdo con la distribución porcentual que se extrae de las mismas, dando lugar al vector que indica el incremento de demanda. Multiplicando dicho vector por la matriz inversa de Leontief se obtiene el efecto inducido sobre la producción $(76,7$ millones de euros), los sueldos y salarios brutos (14,6 millones de euros) y los puestos de trabajo (768 trabajadores).

\section{Impacto recaudatorio del efecto directo, indirecto e inducido}

Partiendo de las premisas establecidas en la metodología, la tasa media de retorno para Cantabria del efecto directo asciende a 0,33 , es decir, de cada euro gastado retorna a la Administración 33 céntimos, como señala la tabla 10. Por lo tanto, el coste neto de cada euro es de 0,67 , ya que el resto se recupera directamente mediante impuestos 0 aportaciones a la Seguridad Social.

Al añadir el efecto indirecto e inducido de la atención a la dependencia, los resultados permiten observar que de cada euro gastado en política social por la Administración Pública, 59,3 céntimos retornan a la Administración vía impuestos y cotizaciones a la Seguridad Social. Si se incorporase la cotización a la Seguridad Social que realizan los cuidadores familiares dados de alta en el Convenio Especial de Cuidadores No Profesionales de Personas en Situación de Dependencia ${ }^{26}$ y el ahorro en prestaciones por desempleo, el retorno sería de 66,46 céntimos.

${ }^{26} \mathrm{~A} 1$ de diciembre de 2010 había en Cantabria 3.597 personas afiliadas a este régimen, cuya cotización es en 2010 de 160,13 euros/mes (158,67 euros de la cuota de la Seguridad Social y 1,46 euros de la cuota de la formación profesional). 


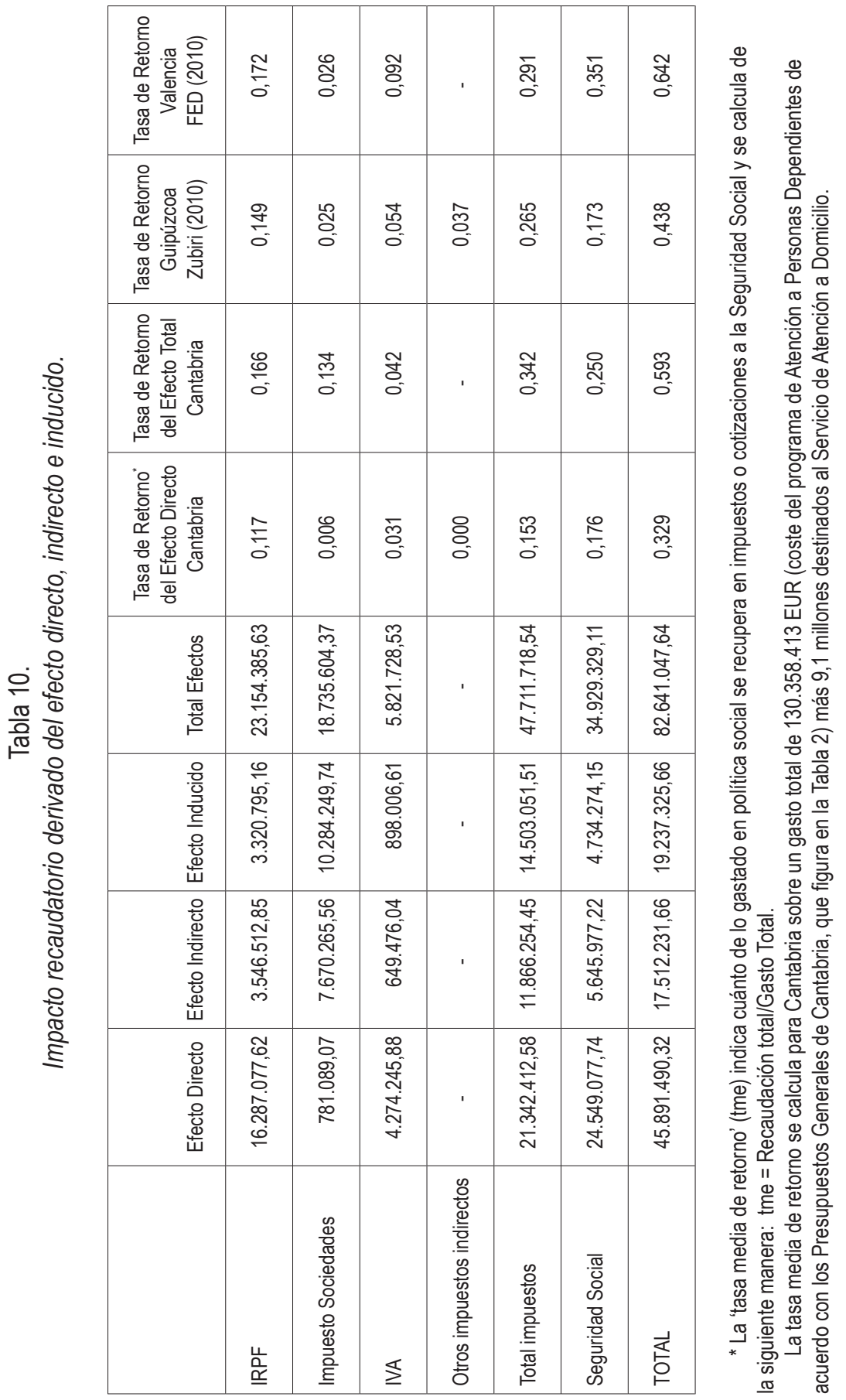




\section{RESUMEN DE RESULTADOS Y CONCLUSIONES}

A continuación se resumen los principales resultados obtenidos del impacto económico del sector de atención a la dependencia:

Tabla 11.

Resumen de resultados y conclusiones.

\begin{tabular}{|c|c|c|c|c|c|}
\hline & $\begin{array}{l}\text { Empleos } \\
\text { (número) }\end{array}$ & $\begin{array}{l}\text { Retribuciones } \\
\text { (EUR) }\end{array}$ & $\begin{array}{l}\text { Producción } \\
\text { (EUR) }\end{array}$ & $\begin{array}{l}\text { Impuestos } \\
\text { (EUR) }\end{array}$ & $\begin{array}{l}\text { Seguridad } \\
\text { Social } \\
\text { (EUR) }\end{array}$ \\
\hline EFECTO DIRECTO & 3.372 & $71.654 .543,00$ & $182.269 .992,56^{*}$ & $21.342 .412,58$ & $24.549 .077,74$ \\
\hline EFECTO INDIRECTO & 889 & $15.602 .784,19$ & $73.426 .536,46$ & $11.866 .254,45$ & $5.645 .977,22$ \\
\hline EFECTO INDUCIDO & 768 & $14.609 .745,33$ & $76.712 .787,38$ & $14.503 .051,51$ & $4.734 .274,15$ \\
\hline TOTAL & 5.029 & $101.867 .072,52$ & $332.409 .316,40$ & $47.711 .718,54$ & $34.929 .329,11$ \\
\hline $\begin{array}{l}\text { Empleos por cada } \\
\text { millón de gasto de la } \\
\text { Administración }\end{array}$ & 36 & & & & \\
\hline $\begin{array}{l}\text { Multiplicador de la } \\
\text { Producción: Producción/ } \\
\text { Gasto Total }\end{array}$ & & & 2,38 & & \\
\hline $\begin{array}{l}\text { Tasa de retorno: } \\
\text { (Impuestos +Seguridad } \\
\text { Social)/ Gasto Total }\end{array}$ & & & & & \\
\hline
\end{tabular}

"Considerando que el Beneficio = Cifra de negocio - Costes y asumiendo que la cifra de negocio iguala a la producción, el efecto directo sobre la producción se calcula a través de la suma de los beneficios calculados para los centros de atención a la dependencia (11.851.838,31 euros) más los costes calculados para estos (161.318.154,25 euros). Asimismo, se considera el valor de la producción del Servicio de Atención a Domicilio estableciendo un valor equivalente al coste que supone para la Administración y que asciende a 9,1 millones de EUR, dado que el beneficio de esta actividad es nulo.

Fuente: Elaboración propia. 
A la vista de estos resultados, cabe establecer las siguientes conclusiones:

- La tasa de retorno de los recursos asignados a este sector es muy alta -de cada euro, 0,59 retornan a la Administración. Si se incluye el ahorro derivado de las prestaciones por desempleo y la cotización a la Seguridad Social de los cuidadores, este retorno asciende en Cantabria a 0,66 euros, situándose en un valor intermedio al observado en otras regiones. La tasa de retorno observada en el País Vasco asciende a 0,43 (Centro de Documentación y Estudios de la Fundación Eguía Careaga, SIIS 1999), en Guipúzcoa a 0,45 (Zubiri et al. 2010) y en la Comunidad Valenciana a 1,26 (Federación Empresarial de Asistencia a la Dependencia 2010).

- El sector de atención a la dependencia resulta intensivo en mano de obra. La generación de empleo asciende a 36 trabajadores por cada millón de euros de gasto de la Administración. Otros estudios situaban este valor entre 23 (Zubiri et al. 2010) y 77 (Federación Vasca de Asociaciones a favor de las Personas con Discapacidad Intelectual o del Desarrollo 2007).

- El multiplicador de la producción asciende a 2,38 de manera que por cada euro gastado por la Administración en el sector, la producción aumenta en 2,38 euros. Estudios previos habían encontrado un valor cercano a 2 (Zubiri et al. 2010).

La inversión en la atención a la dependencia tiene además de los efectos directos e indirectos valorados (traducidos en empleo y generación de riqueza) otros difíciles de cuantificar y que van más allá de la mejora en la calidad de vida de los afectados, como son:

- La capacidad de generar empleo y riqueza vinculada a la innovación y desarrollo tecnológico.

- Es una oportunidad de racionalizar el gasto sanitario con alternativas de menor coste y socialmente más eficaces ${ }^{27}$, reduciendo tanto el consumo de servicios como de productos sanitarios.

- Permite reducir el coste de oportunidad de las familias que se quedan sin posibilidad de trabajar fuera del hogar por tener que atender a un familiar.

En conclusión, los recursos asignados a la atención a la dependencia no deben considerarse como gasto, sino que deben entenderse como inversión no solo económica (traducida en empleo y generación de riqueza) que se cuantifica a través de lo analizado en este estudio, sino también, y como principio general, en cohesión social y en bienestar individual y colectivo, que cabría analizar en futuras investigaciones.

\footnotetext{
${ }^{27}$ Los cuidados paliativos y la rehabilitación cuestan más del doble en un hospital que en un centro residencial. El Libro blanco de la dependencia (2004) cifra el coste de atención del sistema sanitario en 5 veces más que el coste en un centro geriátrico.
} 


\section{REFERENCIAS BibLIOGRÁFICAS}

Birg, H. 2009. "Political impact of demographic change in Germany. A summary view of the causes and consequences of demographic change in Germany and Euroope". Onkologie 32: 3-7.

Cantabria. 2010. "Orden EMP/37/2010, de 18 de marzo, por la que se establecen los criterios y se regula el procedimiento para la acreditación de centros de servicios sociales destinados a la atención a personas en situación de dependencia". Boletín Oficial de Cantabria 64: 11644-11668, 6 de abril de 2010.

Centro de Documentación y Estudios. 1994. El retorno del gasto en servicios sociales. San Sebastián: SIIS.

Centro de Documentación y Estudios. 1999. Estimación del retorno del gasto en servicios sociales y los beneficiarios y trabajadores del sistema en la CAPV. San Sebastián: SIIS.

Centro Europeo de Empresas e Innovación de Galicia. 2008. Guía de actividad empresarial: residencias de la tercera edad. Galicia: BIC. Consultado 6 de febrero de 2010. (http://www.bicgalicia.es/ bicc/guiasadaptadas/descargas/02_residencias_adaptadazona6.pdf).

Centro Europeo de Empresas e Innovación de Navarra. 2003. El inversor privado llama a la puerta de las residencias de ancianos. Navarra: CEIN. Consultado 8 de marzo de 2010. (http://www.cein.es/ web/es/agendanoticias/resumen/emprendedores/2003/02/04/487.php).

Codorniu, J. M. 2005. "Coste de las residencias asistidas de mayores". Instituto de Mayores y Servicios Sociales. Consultado 10 de febrero de 2010 (http://www.imserso.es/ InterPresent1/groups/imserso/ documents/binario/costeramayores.pdf).

Comisión Europea. 2012. Libro Blanco. Agenda para unas pensiones adecuadas, seguras y sostenibles. Consultado el 10 de julio de 2013 (http://EUR -lex.Europa.eu/LexUriServ/LexUriServ.do?uri= COM:2012:0055:FIN:ES:PDF).

Deloitte. 2006. Perspectivas de futuro de los recursos de atención a la dependencia. El sector residencial. Madrid: Deloitte.

Díaz, B. 2012. "Estimación del coste de la atención a la dependencia en centros residenciales y de atención diurna o nocturna". Zerbitzuan 52: 101-117.

Durán, M. ${ }^{a}$ A. 2001. "El análisis de exhaustividad en la economía española". Pp.41-45 en Tiempos, trabajos y género, editado por C. Carrasco. Barcelona: Publicacions de la Universitat de Barcelona.

Dutrénit, J. M. 2005. "Cost-Benefit Analysis in Social Care for Elderly People". Evaluation Review 29: 389-406.

España. 2008. "Resolución de 26 de marzo de 2008, de la Dirección General de Trabajo, por la que se registra y publica el $\mathrm{V}$ Convenio colectivo marco estatal de servicios de atención a las personas dependientes y desarrollo de la promoción de la autonomía personal". Boletín Oficial del Estado 79: 18281-18305, 1 de abril de 2008.

España. 2008. "Resolución de 28 de julio de 2010, de la Dirección General de Trabajo, por la que se registra y publica el XIII Convenio Colectivo General de Centros y Servicios de atención a persona con discapacidad". Boletín Oficial del Estado 198: 72550-72601, 16 de agosto de 2010. 
España. 2010. Tablas salariales correspondientes al año 2010 del convenio colectivo marco estatal de servicios de atención a las personas dependientes y desarrollo de la promoción de la autonomía personal. Boletín Oficial del Estado 52, 1 de marzo de 2010.

Eurostat. 2013. "Pension expenditure projections (baseline scenario)". Economic Policy Comitte. Consultado el 9 de Julio de 2013 (http://epp.eurostat.ec.Europa.eu/tgm/table.do?tab=table\&init=1\&lan guage $=$ en\&pcode=tsdde520\&plugin=0).

Federación Empresarial de Asistencia a la Dependencia. 2010. Estudio sobre los efectos económicos y sociales de una política social orientada a la prestación de servicios y PEVS. Madrid: FED.

Federación Vasca de Asociaciones en favor de las Personas con Discapacidad Intelectual, FEVAS. 2007. Estudio de Impacto Económico de la Discapacidad Intelectual en Euskadi. Bilbao: FEVAS. Consultado el 12 de enero de 2010 (http://sid.usal.es/idocs/F8/FDO20633/Estudio_completo.pdf).

Fernández, P. y R. Barinaga. 2007. "Algunos apuntes sobre el impacto económico del gasto en discapacidad intelectual". Zerbituzuan 42: 57-60.

Fontela, E. 2004. "Leontief and the Future of the World Economy". Pp.30-46 en Wassily Leontief and input-output economics, editado por E. Dietzenbacher and M. Lahr. Cambridge: Cambridge University Press.

Fougere, M. y M. Merette. 1999. "Population ageing and economic growth in seven OECD countries". Economic Modelling 16: 411-427.

Fries, J., C. Koop, J. Sokolov, E. Carson and D. Wright. 1998. "Beyond health promotion: Reducing need and demand for medical care". Health Affairs 17: 70-84.

Gal, Z. 2008. "Inmigration in the United States and the European Union. Helping to solve the economic consequences of ageing?". Sociologia 40: 35-61.

Harvey, P. W. and I. Thurnwald. 2009. "Ageing well ageing productively: The essential contribution of Australia's ageing population to the social and economic prosperity of the nation". Health Sociology Review 18: 379-386.

Instituto Cántabro de Estadística. 2008: Encuesta sobre Discapacidades, Autonomía Personal y Situaciones de Dependencia. Cantabria: ICANE. Consultado el 15 de noviembre de 2010 (http://www. icane.es/society/health-social-welfare).

Institut d'Estadística de Catalunya. 2002. Estadística económica dels establiments d'atenció social a la gent gran. Barcelona: Indescat.

Instituto de Mayores y Servicios Sociales. 2004. Libro Blanco. Atención a las Personas en Situación de Dependencia en España. Madrid: Ministerio de Trabajo y Asuntos Sociales, Secretaria de Estado de Servicios Sociales, Familia y Discapacidad e Instituto de Mayores y Servicios Sociales.

Leontief, W. 1986. Input-output Economics. Nueva York: Oxford University Press.

Martínez, S., M. Dávila, M. ${ }^{a}$ R. Vicente. 2000. “Una aproximación a la evaluación económica de las políticas sociales. El caso del Servicio de Ayuda a Domicilio". Revista del Ministerio de Trabajo y Asuntos Sociales 41: 89-104.

Mirlees, J. 1997. "The economic consequences of ageing populations". Philosoplical Transactions of the Royal Society B: Biological Science 352: 1881-1886. 
Pulido, A. y E. Fontela. 1993. Análisis input-output. Modelos, datos y aplicaciones. Madrid: Pirámide.

Rodríguez, A. y A. Jiménez. 2010. "La atención a la dependencia y el empleo". Working Paper Series 159/2010, Fundación Alternativas. Madrid.

Zubiri, I., J. Martínez y M. Vallejo. 2010. El impacto económico del gasto en política social de la diputación foral de Guipúzcoa. País Vasco: Universidad del País Vasco.

Belén Díaz Díaz es doctora en Ciencias Económica y Empresariales y profesora titular de Economía Financiera en la Universidad de Cantabria. Ha sido investigador visitante en universidades de Reino Unido, Estados Unidos, Australia, Argentina y Chile. Su investigación se centra en las áreas de las finanzas corporativas, la responsabilidad social empresarial y el impacto económico de las políticas sociales. Ha publicado artículos sobre estos temas en revistas como Quarterly Journal of Finance and Accounting, International Journal of Banking, Accounting and Finance, Journal of Economics and Business, Journal of Corporate Ownership \& Control, Journal of Management and Governance, entre otras. Asimismo, ha ocupado cargos de gestión en la Universidad de Cantabria y colabora con entidades públicas y privadas a través de actividades de consultoría y asesoramiento.

RECIBIDO: 29/10/2012

ACEPTADO: $30 / 07 / 2013$ 